\title{
India to set up 80 new units to boost medical research
}

This News story (BMJ 2013;347:f6311, doi:10.1136/bmj.f6311) says that the Department of Health Research of the Ministry of Health and Family Welfare will establish multidisciplinary research units in 80 medical colleges over the next two years,
35 in 2013-14 and 35 in 2014-15. In fact, we should have stated that there will be 35 units set up in 2013-14 and 45 in 2014-15.

Cite this as: BMJ 2013;347:f6353

๑ BMJ Publishing Group Ltd 2013 